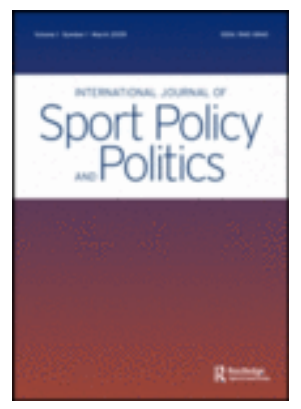

\title{
Public opinion in Japan and the UK on issues of fairness and integrity in sport: implications for anti-doping policy
}

\begin{tabular}{|r|l|}
\hline Journal: & International Journal of Sport Policy and Politics \\
\hline Manuscript ID & RISP-2018-0117.R2 \\
\hline Manuscript Type: & Research Article \\
\hline Keywords: & $\begin{array}{l}\text { World Anti-Doping Code, values education, Japan, United Kingdom, } \\
\text { International Standard for Education }\end{array}$ \\
\hline
\end{tabular}

\section{SCHOLARONE ${ }^{\mathrm{m}}$ Manuscripts}


Table 1: Selected elements of Fiske's four relational models

\begin{tabular}{|c|c|c|c|c|}
\hline Element & Communal sharing & Authority ranking & Equality matching & Market pricing \\
\hline $\begin{array}{l}\text { Significance of } \\
\text { time }\end{array}$ & $\begin{array}{l}\text { Relationships are idealized as } \\
\text { eternal (e.g. solidarity based } \\
\text { on descent or common origin). } \\
\text { Perpetuation of tradition. }\end{array}$ & $\begin{array}{l}\text { Temporal priority to } \\
\text { superiors, often determined } \\
\text { by age or seniority. }\end{array}$ & $\begin{array}{l}\text { Taking of turns, of hosting or } \\
\text { other reciprocation at } \\
\text { appropriate frequency. }\end{array}$ & $\begin{array}{l}\text { Concern with efficient use of time, } \\
\text { spending it effectively and with } \\
\text { the opportunity cost of wasted } \\
\text { time. }\end{array}$ \\
\hline Decision making & $\begin{array}{l}\text { Group seeks consensus, unity, } \\
\text { the sense of the group. }\end{array}$ & $\begin{array}{l}\text { By authoritative decree. Will } \\
\text { of the leader transmitted } \\
\text { through a chain of command. } \\
\text { Subordinates obey orders. }\end{array}$ & $\begin{array}{l}\text { Formal equality e.g. one } \\
\text { person, one vote elections. } \\
\text { Offices rotate or are filled by } \\
\text { lottery. }\end{array}$ & $\begin{array}{l}\text { Market decides; rational cost- } \\
\text { benefit analysis. }\end{array}$ \\
\hline Social influence & $\begin{array}{l}\text { Conformity; desire to be similar } \\
\text { to others, to agree, maintain } \\
\text { unanimity, and not stand out } \\
\text { as different. }\end{array}$ & $\begin{array}{l}\text { Obedience to authority or } \\
\text { deference to prestigious } \\
\text { leaders. }\end{array}$ & $\begin{array}{l}\text { Compliance to return a favour, } \\
\text { taking turns deciding to } \\
\text { maintain balance. }\end{array}$ & $\begin{array}{l}\text { Cost and benefit incentives. } \\
\text { Contracts and bargaining over } \\
\text { terms of exchange. }\end{array}$ \\
\hline $\begin{array}{l}\text { Constitution of } \\
\text { groups }\end{array}$ & $\begin{array}{l}\text { Sense of unity, solidarity, } \\
\text { shared substance (e.g. blood, } \\
\text { kinship). }\end{array}$ & $\begin{array}{l}\text { Followers of a charismatic } \\
\text { leader. Hierarchical } \\
\text { organization. }\end{array}$ & Equal status peer groups. & $\begin{array}{l}\text { Corporations, labour unions, } \\
\text { commodity associations. Rational- } \\
\text { legal organization. }\end{array}$ \\
\hline $\begin{array}{l}\text { Social identity } \\
\text { and the relational } \\
\text { self }\end{array}$ & $\begin{array}{l}\text { Membership of a natural kind } \\
\text { (by ancestry, race, ethnicity, } \\
\text { common origins or common } \\
\text { fate). }\end{array}$ & $\begin{array}{l}\text { Self as revered leader or } \\
\text { loyal follower; identity defined } \\
\text { by rank. }\end{array}$ & $\begin{array}{l}\text { Self as separate but co-equal } \\
\text { peer. }\end{array}$ & $\begin{array}{l}\text { Self defined in terms of } \\
\text { occupation or economic role; how } \\
\text { one earns a living. Identity a } \\
\text { product of entrepreneurial } \\
\text { success or failure. }\end{array}$ \\
\hline Motivation & Intimacy; desire to belong. & Desire for power & Desire for equality. & $\begin{array}{l}\text { Desire for achievement and its } \\
\text { rewards. }\end{array}$ \\
\hline $\begin{array}{l}\text { Moral judgment } \\
\text { and ideology }\end{array}$ & $\begin{array}{l}\text { Caring, kindness and altruism } \\
\text { and generosity. Protecting } \\
\text { intimate personal relations. }\end{array}$ & $\begin{array}{l}\text { Obedience to the will of } \\
\text { superiors. Charismatic } \\
\text { legitimation. }\end{array}$ & $\begin{array}{l}\text { Fairness as strict equality, } \\
\text { equal treatment and balanced } \\
\text { reciprocity. }\end{array}$ & $\begin{array}{l}\text { Abstract, universal, rational } \\
\text { principles based on utilitarian } \\
\text { criterion of the greatest good for } \\
\text { the greatest number. }\end{array}$ \\
\hline $\begin{array}{l}\text { Moral } \\
\text { interpretation of } \\
\text { misfortune }\end{array}$ & $\begin{array}{l}\text { Stigmatisation, isolation as a } \\
\text { pariah. }\end{array}$ & $\begin{array}{l}\text { Have I angered God? Did I } \\
\text { disobey ancesters? }\end{array}$ & $\begin{array}{l}\text { Feeling that misfortune should } \\
\text { be equally distributed. That } \\
\text { 'things will even out'. }\end{array}$ & $\begin{array}{l}\text { Was this a reasonably expectable } \\
\text { risk or calculable cost to pay for } \\
\text { the benefits sought? }\end{array}$ \\
\hline
\end{tabular}


Table 2. Representativeness of the two samples ( $\%$ breakdown of $15-79$ population)

\begin{tabular}{|l|l|l|l|l|}
\hline \multicolumn{5}{|c|}{ Japan } \\
\hline Age range & $15-19$ & $20-39$ & $40-59$ & $60-79$ \\
\hline Survey & $24 \%$ & $25 \%$ & $25 \%$ & $25 \%$ \\
\hline $\begin{array}{l}\text { Population } \\
\text { September } \\
2017)\end{array}$ & $6 \%$ & $27 \%$ & $35 \%$ & $32 \%$ \\
\hline Tokyo & $32.7 \%$ & & & \\
\hline Other & $67.3 \%$ & \multicolumn{1}{|c|}{ UK } & \\
\hline \multicolumn{5}{|l|}{} \\
\hline Age range & $15-19$ & $20-39$ & $40-59$ & $60-79$ \\
\hline Survey & $1 \%$ & $37 \%$ & $34 \%$ & $28 \%$ \\
\hline Population & $8 \%$ & $34 \%$ & $35 \%$ & $23 \%$ \\
\hline
\end{tabular}


Table 3: Overview of selected aggregate data (\%)

\begin{tabular}{|c|c|c|c|c|c|c|c|c|c|c|c|c|c|c|c|}
\hline & & \multicolumn{2}{|c|}{ All } & \multicolumn{2}{|c|}{ Males } & \multicolumn{2}{|c|}{ Females } & \multicolumn{2}{|c|}{$15-19$} & \multicolumn{2}{|c|}{$20-39$} & \multicolumn{2}{|c|}{$40-59$} & \multicolumn{2}{|c|}{$60-79$} \\
\hline & & $J$ & UK & $J$ & UK & $J$ & UK & $\mathrm{J}$ & UK & $\mathbf{J}$ & UK & $\mathrm{J}$ & UK & $J$ & UK \\
\hline \multirow[t]{2}{*}{$\begin{array}{l}\text { Frequency of } \\
\text { participation. }\end{array}$} & $\begin{array}{l}3+\text { per } \\
\text { week }\end{array}$ & 21 & 33.9 & 22.9 & 34.8 & 19.1 & 33.0 & 22.5 & 30.2 & 12.8 & 35.4 & 15.9 & 33.7 & 32.8 & 32.6 \\
\hline & Never & 36.6 & 20.2 & 33.0 & 21.1 & 40.0 & 19.4 & 29.5 & 9.3 & 42.8 & 9.7 & 43.7 & 23.8 & 29.9 & 28.6 \\
\hline \multirow[t]{2}{*}{$\begin{array}{c}\text { Frequency of } \\
\text { watching at venue }\end{array}$} & $\begin{array}{l}1+\text { per } \\
\text { week }\end{array}$ & 4.2 & 3.0 & 4.9 & 4.6 & 3.5 & 1.6 & 5.9 & 5.4 & 4.3 & 4.3 & 3.1 & 3.0 & 3.7 & 1.5 \\
\hline & Never & 65.9 & 71.6 & 62.8 & 60.5 & 68.9 & 81.5 & 58.7 & 70.3 & 67.3 & 64.0 & 69.7 & 73.6 & 67.6 & 77.9 \\
\hline \multirow{2}{*}{$\begin{array}{l}\text { Watched/listened } \\
\text { to sport on } \\
\text { TV/radio }\end{array}$} & $\begin{array}{l}\text { 1+per } \\
\text { week }\end{array}$ & 23.7 & 26.3 & 29.0 & 39.0 & 18.6 & 14.6 & 16.4 & 7.9 & 17.7 & 20.1 & 22.2 & 27.3 & 38.2 & 32.7 \\
\hline & Never & 23.5 & 33.3 & 20.8 & 21.6 & 26.2 & 44.1 & 28.9 & 55.3 & 30.2 & 36.0 & 22.3 & 34.3 & 13.1 & 28.4 \\
\hline
\end{tabular}

Note: The number of 15-19 respondents in the UK (47) was very small and the percentage figures need to be treated with caution. 
Table 4. Reasons for opposing doping in sport (\%)

\begin{tabular}{|l|l|l|l|l|l|l|}
\hline & $\begin{array}{l}\text { Japan } \\
\text { All }\end{array}$ & UK All & $\begin{array}{l}\text { Japan } \\
\text { males }\end{array}$ & $\begin{array}{l}\text { UK } \\
\text { males }\end{array}$ & $\begin{array}{l}\text { Japan } \\
\text { females }\end{array}$ & $\begin{array}{l}\text { UK } \\
\text { females }\end{array}$ \\
\hline Undermines the spirit of sport & 19.1 & 46.5 & 21.6 & 48.1 & 16.6 & 45.0 \\
\hline Against the spirit of fair play & 50.2 & 39.6 & 46.9 & 38.2 & 53.5 & 40.8 \\
\hline Harms the athlete's health & 17.0 & 3.7 & 17.7 & 3.3 & 16.2 & 4.0 \\
\hline $\begin{array}{l}\text { Against the values of my } \\
\text { country }\end{array}$ & 9.8 & 3.8 & 9.7 & 3.2 & 10.0 & 4.4 \\
\hline It is a short-cut to a goal & 3.9 & 6.5 & 4.1 & 7.2 & 3.7 & 5.8 \\
\hline
\end{tabular}

Note. The options 'Other' and 'Don't Know' have been excluded from the Table. 
Table 5. Important values in sport by gender (\%)

\begin{tabular}{|l|l|l|l|l|l|l|}
\hline & Japan All & UK All & Japan & UK & Japan & UK \\
males & males & females & females \\
\hline $\begin{array}{l}\text { Meet human needs for } \\
\text { physical movement }\end{array}$ & 17.0 & 8.2 & 17.7 & 8.7 & 15.6 & 7.8 \\
\hline Improve health & 22.1 & 19.3 & 21.7 & 18.0 & 22.4 & 20.8 \\
\hline Learn respect for rules & 10.4 & 10.9 & 11.5 & 12.4 & 9.6 & 9.7 \\
\hline $\begin{array}{l}\text { Acquire/ understand spirit } \\
\text { of fair play }\end{array}$ & 11.2 & 23.2 & 11.5 & 23.5 & 10.9 & 23.1 \\
\hline Work towards goals & 20.8 & 7.9 & 19.5 & 6.8 & 21.6 & 7.9 \\
\hline Friendship & 10.5 & 18.3 & 9.6 & 18.0 & 11.2 & 18.5 \\
\hline Build better society & 5.9 & 7.0 & 5.8 & 7.3 & 6.1 & 6.8 \\
\hline $\begin{array}{l}\text { Build better international } \\
\text { society }\end{array}$ & 2.8 & 5.3 & 2.8 & 5.2 & 2.6 & 5.4 \\
\hline
\end{tabular}

Note. The data in this table are aggregates of the multiple selections made by respondents 
Table 6: Overview of (selected) aggregate data (\%)

\begin{tabular}{|c|c|c|c|c|c|c|c|c|c|c|c|c|c|c|c|}
\hline & & \multicolumn{2}{|c|}{ All } & \multicolumn{2}{|c|}{ Males } & \multicolumn{2}{|c|}{ Females } & \multicolumn{2}{|c|}{$15-19$} & \multicolumn{2}{|c|}{$20-39$} & \multicolumn{2}{|c|}{$40-59$} & \multicolumn{2}{|c|}{$60-79$} \\
\hline & & $\mathrm{J}$ & UK & $\mathrm{J}$ & UK & $\mathrm{J}$ & UK & $\mathrm{J}$ & UK & $\mathrm{J}$ & UK & $J$ & UK & $\mathrm{J}$ & UK \\
\hline \multirow{2}{*}{$\begin{array}{l}\text { Taking illegal } \\
\text { substance as } \\
\text { opponent done } \\
\text { same }\end{array}$} & Unfair & 84.4 & 81.4 & 86.1 & 76.7 & 82.5 & 85.1 & 78.4 & 64.3 & 81.4 & 77.2 & 86.6 & 84.1 & 89.3 & 90.3 \\
\hline & Fair & 15.6 & 18.6 & 13.9 & 23.3 & 17.5 & 14.9 & 21.6 & 35.7 & 18.6 & 22.8 & 13.4 & 15.9 & 10.7 & 9.7 \\
\hline \multirow{2}{*}{$\begin{array}{c}\text { Taking same PEDS } \\
\text { but receiving longer } \\
\text { ban than in other } \\
\text { sport } \\
\end{array}$} & Unfair & 62.9 & 66.2 & 59.8 & 63.5 & 65.9 & 68.5 & 61.6 & 72.0 & 61.7 & 64.0 & 65.1 & 67.1 & 63.0 & 68.1 \\
\hline & Fair & 37.1 & 33.8 & 40.2 & 36.5 & 34.1 & 31.5 & 38.4 & 28.0 & 38.3 & 36.0 & 34.9 & 32.9 & 37.0 & 31.9 \\
\hline \multirow{2}{*}{$\begin{array}{l}\text { Unable to sleep so } \\
\text { take energy drink } \\
\text { before competition }\end{array}$} & Unfair & 32.1 & 26.3 & 33.5 & 22.7 & 30.9 & 29.3 & 23.1 & 11.5 & 29.6 & 18.8 & 39.7 & 28.3 & 36.8 & 34.5 \\
\hline & Fair & 67.9 & 73.7 & 66.5 & 77.3 & 69.1 & 70.7 & 76.9 & 88.5 & 70.4 & 81.3 & 60.3 & 71.7 & 63.2 & 65.5 \\
\hline \multirow{2}{*}{$\begin{array}{c}\text { Access to latest } \\
\text { technology and } \\
\text { now winning }\end{array}$} & Unfair & 38.9 & 35.8 & 41.4 & 31.2 & 36.3 & 39.9 & 40.0 & 46.9 & 41.1 & 43.6 & 38.1 & 30.6 & 36.4 & 31.8 \\
\hline & Fair & 61.1 & 64.2 & 58.6 & 68.8 & 63.7 & 60.1 & 60.0 & 53.1 & 58.9 & 56.4 & 61.9 & 69.4 & 63.6 & 68.2 \\
\hline \multirow{2}{*}{$\begin{array}{l}\text { Had laser eye } \\
\text { surgery and now } \\
\text { winning }\end{array}$} & Unfair & 13.2 & 5.0 & 14.4 & 5.9 & 11.9 & 4.2 & 15.7 & 10.5 & 15.1 & 8.3 & 11.9 & 3.3 & 10.5 & 2.2 \\
\hline & Fair & 86.8 & 95.0 & 85.6 & 94.1 & 88.1 & 95.8 & 84.3 & 89.5 & 84.9 & 91.7 & 88.1 & 96.7 & 89.5 & 97.8 \\
\hline \multirow{2}{*}{$\begin{array}{l}\text { Lose prelim. round } \\
\text { intentionally to } \\
\text { avoid tough } \\
\text { opponent }\end{array}$} & Unfair & 58.4 & 70.4 & 53.9 & 62.7 & 63.0 & 78.9 & 51.1 & 65.4 & 49.4 & 68.2 & 61.4 & 68.7 & 70.2 & 76.8 \\
\hline & Fair & 41.6 & 29.6 & 46.1 & 37.3 & 37.0 & 21.1 & 48.9 & 34.6 & 50.6 & 31.8 & 38.6 & 31.3 & 29.8 & 23.2 \\
\hline \multirow{2}{*}{$\begin{array}{l}\text { Intentionally put } \\
\text { opponent at a } \\
\text { disadvantage }\end{array}$} & Unfair & 50.2 & 39.3 & 43.0 & 35.0 & 57.7 & 43.6 & 44.4 & 60.0 & 43.1 & 35.2 & 51.5 & 35.8 & 60.1 & 48.5 \\
\hline & Fair & 49.8 & 60.7 & 57.0 & 65.0 & 42.3 & 56.4 & 55.6 & 40.0 & 56.9 & 64.8 & 48.5 & 64.2 & 39.9 & 51.5 \\
\hline \multirow{2}{*}{$\begin{array}{l}\text { Make fun of rival } \\
\text { during competition }\end{array}$} & Unfair & 69.0 & 71.0 & 63.8 & 63.9 & 74.1 & 79.5 & 71.5 & 79.3 & 66.7 & 66.8 & 68.3 & 70.5 & 69.8 & 79.4 \\
\hline & Fair & 31.0 & 29.0 & 36.2 & 36.1 & 25.9 & 20.5 & 28.5 & 20.7 & 33.3 & 33.2 & 31.7 & 29.5 & 30.2 & 20.6 \\
\hline
\end{tabular}


Figure 1. Attitudes towards doping in sport by extent of participation in sport (Japan) \%

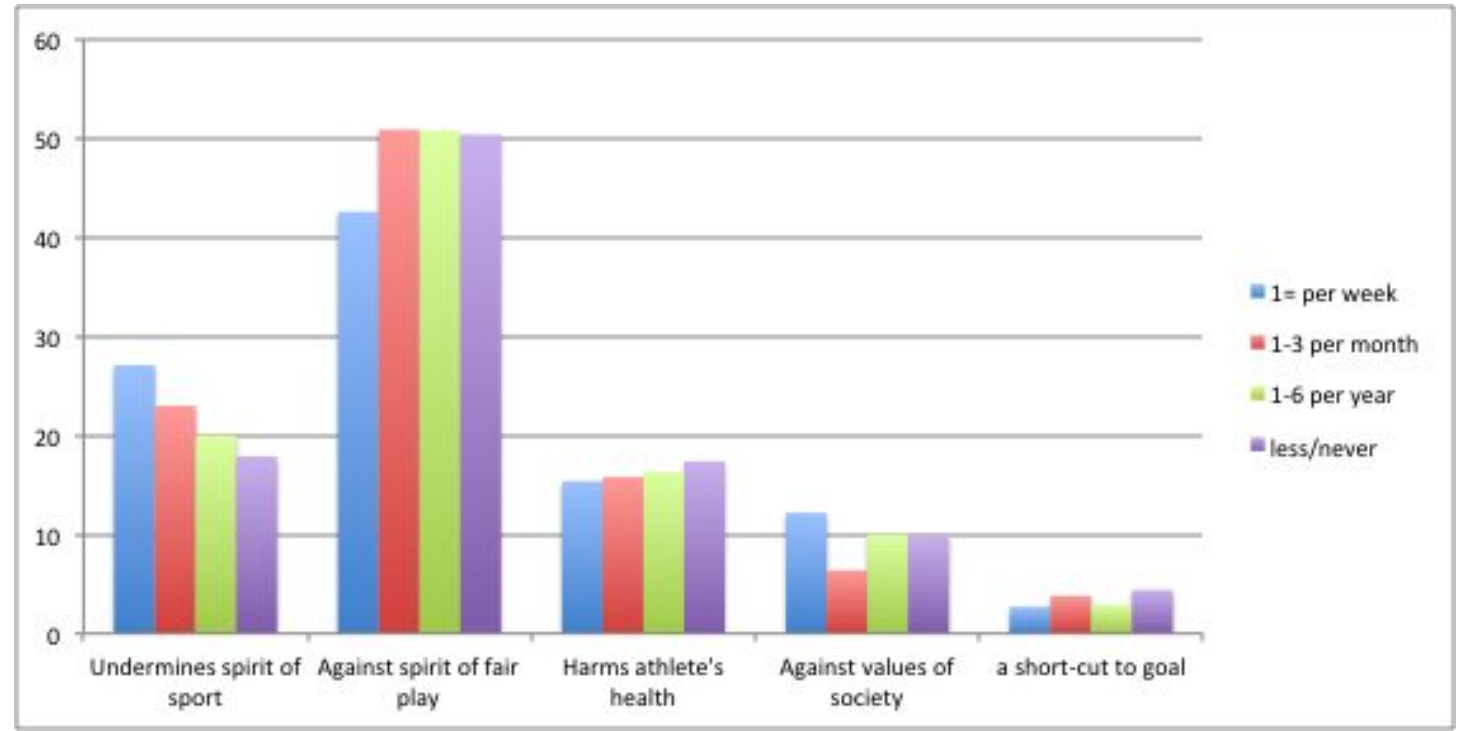


Figure 2. Attitudes towards doping in sport by extent of participation in sport (UK) \%

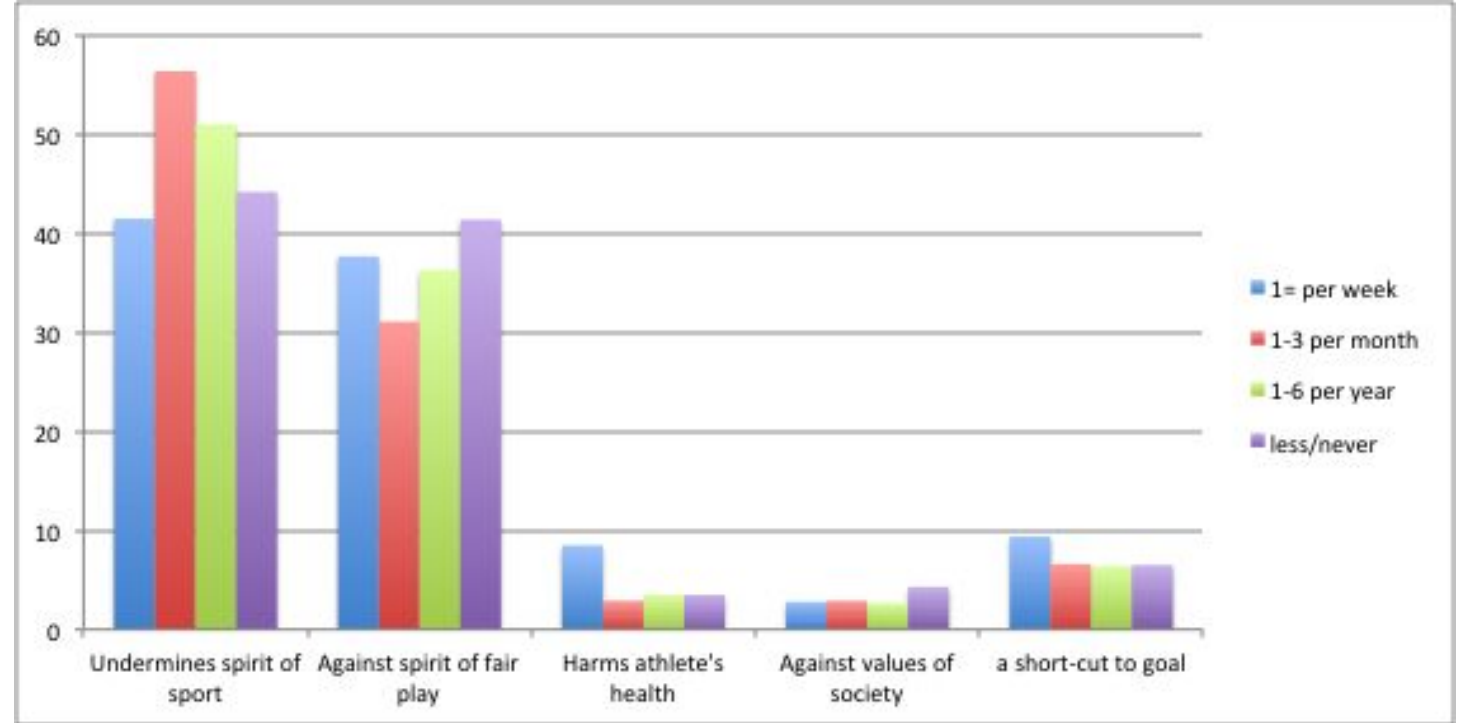


Figure 3. Frequency of playing sport and the assessment of actions as 'unfair' (\%)

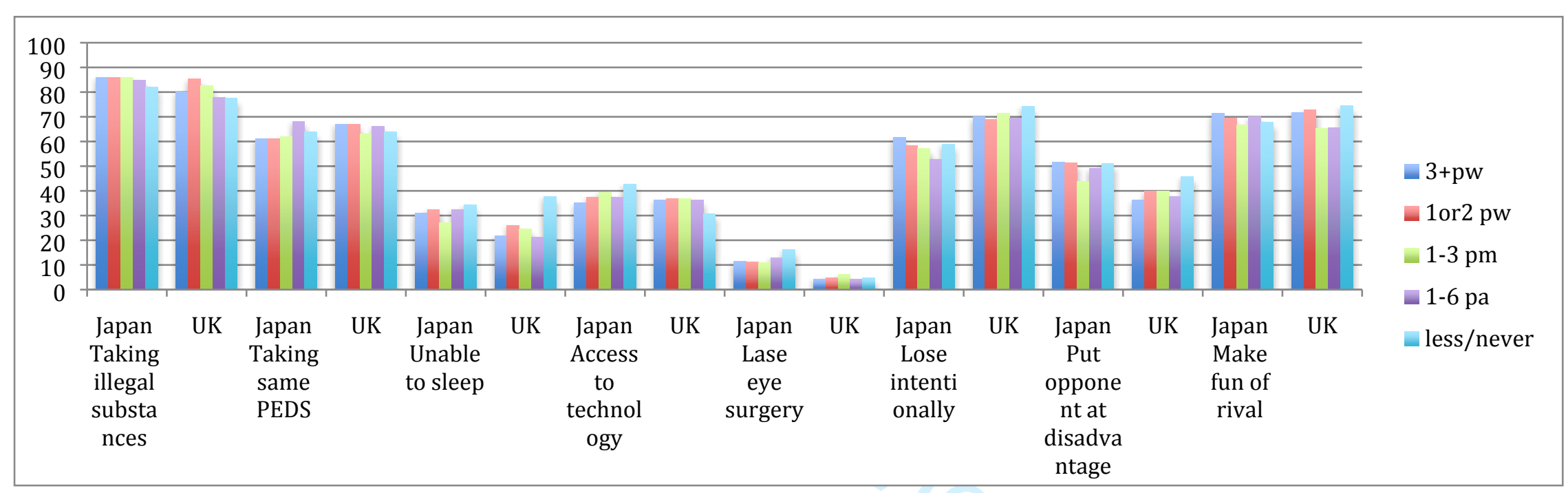


Figure 4. Assessment of actions as 'unfair' or 'very unfair' by males in four age groups (\%)

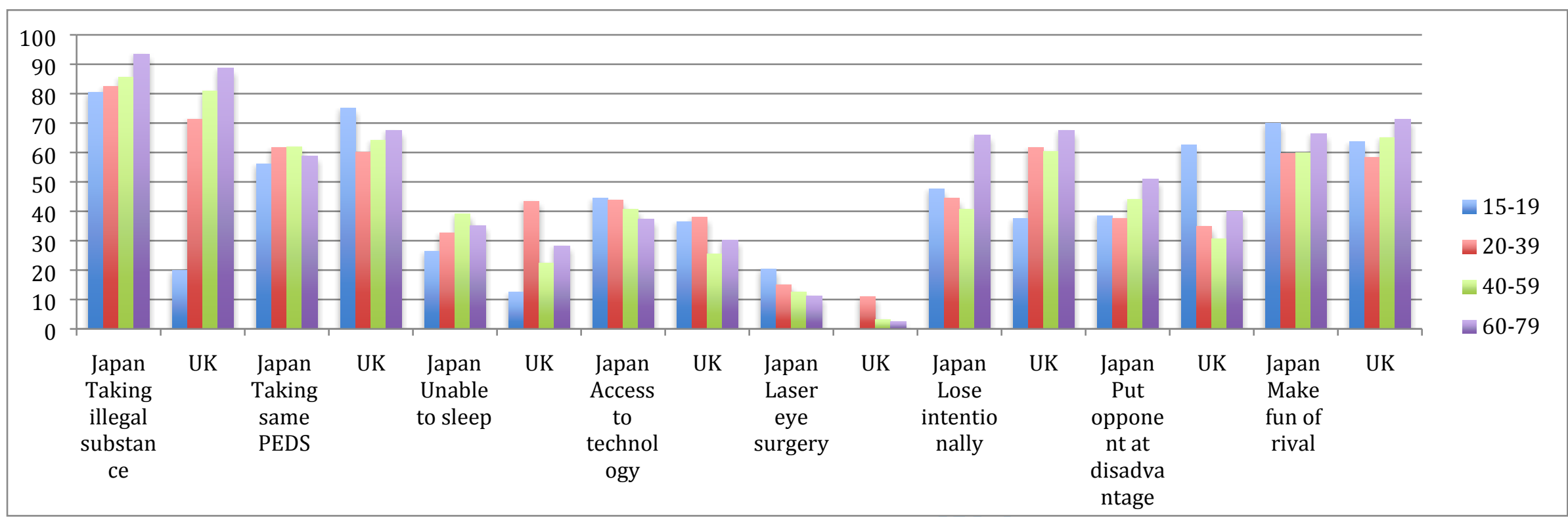


Figure 5. Assessment of actions as 'unfair' by females in four age groups (\%)

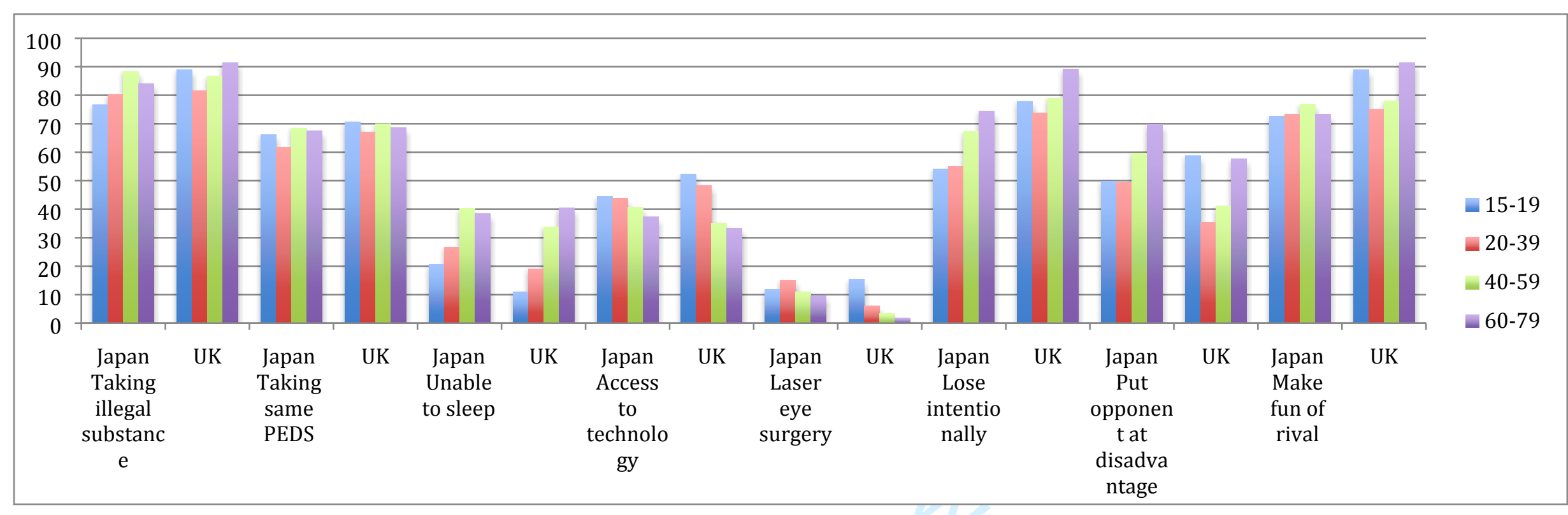




\title{
Appendix: Public survey in JAPAN
}

\author{
QUESTIONS \\ *texts in blue:
}

[japan1] How often, if at all, have you played sport or done physical exercise over the past year? (Please include any competitive sport, walking and light physical movement)

$<1>$ Three or more a week

$<2>$ One or two times a week

$<3>$ Between one to three times a month (i.e. more than once a month)

$<4>$ Between one and six times a year (i.e. more than once a year)

$<5>$ None at all

\#\# To those who answered 1-4 in japan1

[japan2 if japan1 in $[1,2,3,4]$ ] \{multiple order=randomize max=3\} Which two or three, if any, of the following are reasons why you have played sport/ done physical exercise over the past year?

Please choose up to three answers.

$<1>$ For my health/ to improve my fitness

$<2>$ Because I enjoy it/ it is something to do in my spare time

$<3>$ Because I need to do more exercise

$<4>$ So I can challenge myself

$<5>$ To spend time with friends

$<6>$ To spend time with my family

$<7>$ To improve my ability and skills in sport

$<8>$ To improve how I look

$<9>$ Because l've been inspired/encouraged by major sporting events (e.g. 2020 Tokyo Olympics/

Paralympics)

$<10>$ Because it is a popular thing to do

$<11>$ Don't know

\#\# To those who answered 5 in japan1

[japan3 if japan1 in [5] \{multiple order=randomize max=3\} You previously said that haven't done any exercise in the past year...<<br/ $>>$ Which, if any, of the following are reasons why you did not play sport/ do physical exercise over the past year? Please choose up to three answer options.

$<1>$ Because I don't have enough time (due to e.g. work or housework)

$<2>$ Because I am not (physically) strong enough

$<3>$ Because I am getting old/ Because of my age

$<4>$ Because I don't like physical exercise or sport

$<5>$ Because there is no place or facility near me to do sport

$<6>$ Because I don't have the chance to do any sport (e.g. because of social barriers)

$<7>$ Because I have no friends/ family to go with

$<8>$ Because it costs too much money

$<9>$ Because I do not have anyone to train/ instruct me

$<10$ fixed xor $>$ None of the above

$<11$ fixed xor> Don't know

[japan4] Over the past year, approximately how often, if at all, have you watched a sport event in person at the venue? (This can include watching any free or paid-for major or local sporting event e.g. cheering along the road for a marathon, watching a football match in the stadium)

$<1>$ Once a week or more

$<2>$ Between one and three times a month (i.e. more than once a month) 
$<3>$ Between one and six times a year (i.e. a few times a year)

$<4>$ None at all

[japan5] Over the past year, how often, if at all, have you watched sport on TV or listened to sport on the radio? (Please only think about listening/ watching live or recorded matches and do NOT include watching highlights of sport on the news or sports documentaries)

$<1>$ Once a week or more

$<2>$ Between one and three times a month (i.e. more than once a month)

$<3>$ Between one and six times a year (i.e. a few times a year)

$<4>$ None at all

\#\# Options 1 and 2 can both be selected

[japan6] \{multiple\} Have you ever watched the Olympic or Paralympic Games at an official stadium/ venue?

$<1>$ Yes, I watched at least one event at a 1964 Tokyo Olympic or Paralympic stadium/ venue

$<2>$ Yes, I watched at least one event at a different Olympic or Paralympic Games at one of the stadium/ venue

$<3$ fixed xor $>$ No, never

\#\# Options 1 and 2 can both be selected

[japan7] \{multiple\} Have you ever watched or listened to the Olympic or Paralympic Games on TV or on the radio? (Please only think about listening or watching live or recorded matches but do NOT include watching sports highlights on the news or sport documentaries.)

$<1>$ Yes, I watched the 1964 Tokyo Olympic or Paralympic Games live or recorded on TV/ radio

$<2>$ Yes, I have watched a different Olympic or Paralympic Games live or recorded on TV/ radio $<3$ fixed xor $>$ No, never

[japan8] How happy or unhappy were you that the 2020 Olympic and Paralympic Games were awarded to Tokyo?

$<1>$ Very happy

$<2>$ Fairly happy

$<3>$ Fairly unhappy

$<4>$ Very unhappy

[japan9] \{multiple order=randomize max $=3$ \} When thinking about sport in general, which two or three, if any, of the following values do you think are the most important? Please choose up to three answers.

$<1>$ Physical ability

$<2>$ Promoting health

$<3>$ Discipline and rules

$<4>$ Fair play and good sportsmanship

$<5>$ Setting and achieving goals

$<6\rangle$ Building teamwork and friendship

$<7>$ Contributing in a positive way to the local community

$<8>$ Contributing in a positive way to the global community

\#\# This only goes to those aged 15 and over

[japan10] \{grid roworder=randomize displaymax=5\} Imagine you are an athlete, how fair or unfair do you think the following things related to sport are? 
- [japan10_1] Taking an illegal substance (i.e. any substance prohibited by the World Anti-Doping Code) as you know your opponent has done the same

- [japan10_2] Taking the same illegal substance (i.e. any substance prohibited by the World AntiDoping Code) but receiving a longer ban from competing compared to athletes in other sports who took the same substance due to different sports' anti-doping rules at international competitions - [japan10_3] You could not sleep well the previous night before a competition so in the morning you drank an energy drink which claimed to increase your stamina

- [japan10_4] Unlike other athletes, you have access to the latest sport technology in your sport and are now winning competitions

- [japan10_5] You used to wear glasses for competitions, but had laser eye surgery. You improved your performances and are now winning a number of competitions

- [japan10_6] You lose a preliminary round match intentionally in order to avoid a tough opponent in the next round

- [japan10_7] You intentionally put your opponent at a disadvantage (i.e. doing something that is allowed but is considered strategic or tactical play)

- [japan10_8] You make fun of a rival during a competition

$<1>$ Unfair

$<2>$ Fair

$<3>$ Don't know

\#\# To those who said 'Unfair' to any of the above statements in Q10

[japan11_1_8 if japan10 in [1]] \{single order=randomize\} Which one of the following best describes why you think this is generally unfair?

$<1>$ Because it means there aren't equal conditions between the athletes

$<2>$ Because it is against the norm, principle, ethics of sport

$<3>$ Because it is against the values and norms of society

$<4>$ Because it disrespects the values of relationships with other humans

$<5>$ Because other competitors are not being respected

$<6>$ Because of the expectations of other people (e.g. parents, sponsors, fans etc.)

$<7>$ Because it is against my own values and beliefs

[japan12] \{single order=randomize $\}$ Which one of the following best describes your opinion of doping in sport?

$<1>$ It undermines the spirit of sport

$<2>$ It is against the spirit of fair play

$<3>$ It harms the athlete's health

$<4>$ It is against the values of society

$<5>$ It is seen as a short-cut to the goal

$<6$ fixed $>$ Not sure

[japan13] \{grid roworder=randomize displaymax $=6$ \} To what extent do you agree or disagree that the following messages have been successfully communicated about this country to other countries after Britain hosted the Tokyo 2020 Olympic and Paralympic Games?

- [japan13a] Japan is a society that generally respects high ethical standards

- [japan13b] Japan is a society that respects laws and rules

- [japan13c] Japan is a society that generally respects high ethical standards in sport

- [japan13d] Japan is a society that respects sporting rules and principles

- [japan13e] Japanese people have respectable personal values and principles 
- [japan13f] Japan is a strong economic power

- [japan13g] Japan has close-knit communities and good infrastructure (e.g. buildings, transport)

- [japan13h] Japan is technologically advanced

- [japan13i] Japan is a traditional society

- [japan13j] Japan allows people to have an good lifestyle

- [japan13k] Japan promotes global peace and international development

- [japan13I] Japan tackles inequalities related to, for example, race, religion, political beliefs and gender

$<1>$ Strongly agree

$<2>$ Tend to agree

$<3>$ Neither agree nor disagree

$<4>$ Tend to disagree

$<5>$ Strongly disagree

[japan14] \{multiple order=randomize max $=5\}$ Which, if any, of the following do you think are required to be a professional national athlete competing for your country? Please choose up to 5 answers.

$<1>$ Strong body

$<2>$ Strong mind

$<3>$ Perform well

$<4>$ Ability to win competitions or matches

$<5>$ Strong personality

$<6>$ Be a good role model to young people

$<7>$ Good decision-making skills

$<8>$ Pushing the limits of physical and mental health in honest ways

$<9>$ Enjoy sport

$<10>$ Emotion and passion for sport

$<11>$ A sincere attitude to sport

$<12>$ Respect for justice and fair play

$<13>$ Ability to face and overcome challenges

$<14>$ Hard work and determination

$<15>$ Follow the sport's principles or rules (e.g. anti-doping rules)

$<16>$ Have ethical values

$<17>$ Respect for others without discrimination

$<18>$ Respect for teamwork 
Anti-doping efforts at both the national and global levels operate within a framework of regulation and increasingly, at the national level, a framework of civil and criminal law. The global regulatory framework, in the form of the World Anti-Doping Code (hereinafter 'the Code'), came into force in January 2004 and has been regularly revised with a fourth version due in 2021. The Code was given a legal foundation in 2007 when the UNESCO Convention Against Doping in Sport came into force. By mid-2017 187 countries had ratified the Convention. However, the existence of a gap between formal ratification and compliance, defined as the enthusiastic embrace of the values of the Convention and the commitment of resources necessary for effective enforcement, is well documented (Hanstad and Loland 2008, Wagner and Hanstad 2011, Houlihan 2014). Among the explanations for the variation in compliance is the lack of capacity (such as finance, scientific expertise and management) of many countries (Houlihan and Garcia 2012) and the lack of political will (WADA 2012). The continuing challenge of achieving compliance had led WADA to place an increasing emphasis on strengthening anti-doping values rather than relying solely on detection and deterrence. Education was given a much higher and clearer profile in the 2015 iteration of the Code and in 2017 WADA established a working group to prepare an International Standard (IS) 'which would elevate the importance of valuesbased education within the World Anti-Doping Program' (WADA 2017). The draft IS emphasised that 'The overall guiding purpose of the International Standard for Education (ISE) is to support the preservation of the spirit of sport ...' (WADA 2018 p.4). The education programmes should inter alia 'instill values' (p. 14) and deliver 'activities that place the development of an individual's personal values and principles at the heart of their evolving sport experience' (p.15). While the primary target group 
for the ISE is elite athletes the Standard also identified young people (in schools and sports clubs), parents and the media as target groups (p. 21).

Part of the explanation for the increased emphasis on values-based education is that even among countries that possess adequate resources and where governments demonstrate value-commitment to anti-doping (for example, by adequate resource allocation, an active and accountable National Anti-Doping Organisation (NADO) and involvement in international anti-doping organisations and forums such as WADA and the Council of Europe) variation in compliance remains evident. One possible explanation for this variation might be low levels of public support for antidoping. At the recent conference in Oslo, 'Clean Sport = Fair Outcome?', a number of participants emphasised the importance of public attitudes and support. Travis Tygart, CEO of the US Anti-doping Agency, commented that the 'confidence of the public was crucial', a view that was echoed by Linda Helleland, WADA Vice-chair and Norwegian Minister for Sport, who stressed the need to 'maintain public trust' in WADA and anti-doping. ${ }^{1}$ It was generally acknowledged that an important element in maintaining governmental commitment was consistent and strong public support. However, evidence of a deep understanding of public opinion on doping and integrity in sport is scant. Among anti-doping advocates there is an assumption that the 'spirit of sport', the key value statement in the Code, is understood in similar ways across the globe and possesses similar moral and normative weight.

The aims of this paper are to explore the utility of the 'spirit of sport' as a moral reference point, to assess the significance of cultural values for successful Code

\footnotetext{
${ }^{1}$ Quotes are from notes made by one of the authors who attended the conference held in Oslo on $25^{\text {th }}$ June 2018.
} 
compliance and to contribute to the development of values-based education programmes. A clear understanding of the relationship between public opinion, domestic rule/law-making and athlete education is important for three reasons. First, WADA is encouraging governments to support the Code with domestic legislation. Second, if values-based education of elite athletes is to be prioritised it is important to know the extent to which WADA-defined values, such as the spirit of sport, will be recognised and reinforced at the general societal level. Third, it is important for WADA to acknowledge the extent to which its core value, the spirit of sport, is understood globally.

The article begins with a review of research into the relationship between law/rulemaking and cultural values/public opinion. This review is followed by a summary of current knowledge about public opinion towards doping in sport and towards antidoping rule violations. The results from the surveys of public opinion in Japan and the UK are then presented and analysed before the implications of the analysis for Code compliance and anti-doping values-based education are explored. Whilst the research identifies that both countries strongly condemn-doping in sport - with some nuance for the UK this is primarily expressed through sporting values, whereas for Japan broader cultural values are an important reference point.

\section{Public opinion, law-making and behavioural change}

There are two basic perspectives on the relationship between public opinion and the introduction and application of laws (Thomas et al. 1976). The conflict perspective 
suggests that laws and other regulatory forms are the outcome of competition and conflict between interests and that the various interests related to doping (governments, international federations, broadcasters, event organisers etc.) will aim to introduce regulations/laws that are most supportive of their organizational objectives. Policy actors will base their opinion of proposed regulations and laws on strategic moral rules 'which fluctuate within and between cultures as opposed groups struggle for control' (DeScioli \& Kurzban 2012, p.16). Interests will also seek to influence the ways in which regulations and laws (for example therapeutic use exemptions (TUEs)) are interpreted and enforced. The regulations/laws that address the issue of doping in sport are, according to this perspective, seen as the outcome of a power struggle between interests and have only a weak relationship to public opinion.

In marked contrast, the consensus perspective, gives a central role to public opinion and 'suggests that ... law is essentially a codification of the values of a people' (Thomas et al. 1976, p.110). While there is considerable evidence that policy actors in sport will seek to protect their interests when faced with proposed regulatory changes research designed to test hypotheses derived from these two competing perspectives suggests that the consensus perspective has the greater weight of empirical support. In other words the decisions about rules that are the outcome of the competition between interests still require public support if they are to be effective (Page and Shapiro 1983; 2010, Burstein 2003).

Drafting rules and laws that are the outcome of competition between interests and that have public support is challenging at the national level, but substantially more so at 
the global level. There is considerable evidence that an individual's values are strongly influenced by the socio-cultural context in which they live with religion or secular philosophy (such as Confucianism) being particularly important. For example, in relation to drug use Protestantism emphasises self-discipline and control in the belief that the body was given to a person by God and there was consequently a duty to take care of it (Thomas 1997). Courtwright (1997) points out that within predominantly Christian countries it is only in Protestant countries that strong alcohol prohibition movements have been successful: southern European Catholic countries appear far more tolerant. It is notable that many of the leading countries in antidoping have either a Protestant individualistic culture ${ }^{2}$ (Norway, Canada, UK, Germany and the Netherlands for example) or are countries with a strong tradition of harmony, community and order such as Japan (and other countries with a Confucian tradition) (see Oshida 1983, Ikenami 2005, Fairbank et al. 1973).

The significance of national culture for public opinion is explored by Fiske (1992) who identifies four models of social relations (communal sharing, authority ranking, equality matching, market pricing) that affect how individuals interact with others and assess the behaviour of others (see Table 1). Although most countries are a mix of more than one model Fiske argued that communal sharing was the dominant model in Japan. Communal sharing emphasises the importance of 'Consensus, unity and conformity' and being united by a common identity with the result that 'people seek the sense of the group, contributing ideas not as individual positions but as part of the search for a joint judgment' (1992, p.697; see also Doi 1981, Morita 2011). In

\footnotetext{
${ }^{2}$ All these countries were early signatories of the Council of Europe Anti-Doping Convention, are prominent within WADA (as personnel or host country) and have NADOs that have been consistently (and reasonably well) funded by their governments.
} 
contrast to the communal sharing model the UK is closer to the market pricing model according to which human behaviour is underpinned by a set of values derived from the assumption that 'all human social behaviour is based on more or less rational calculations of cost-benefit ratios in self-interested exchanges' (Fiske 1992, p.706). According to this model the rational individual operates in a world of formal rules and those who break the rules (on doping in sport for example) 'get what they deserve (they are "failures") and that the logical consequence of free choice is paying for one's mistakes' (1992, p.708).

\section{Table 1 about here}

While it is generally accepted that the state within which a person lives is a significant, if not the primary, influence on and reflection of their moral judgments it is difficult to specify precisely the importance of the state in relation to other cultural reference points. In many countries in the contemporary world identity is multiple, complex and layered (by nation, family, status group, ethnicity, gender and religion, for example). However, with an acknowledgement of the relative weakness of the research evidence the studies reported in this section would suggest that while nonstate factors such as gender (Gilligan 1982) and religion (Hood et al. 1996) have some impact on moral assessments the most important factor shaping perceptions of fairness and unfairness is the state. The state through the cumulative process of lawmaking and enforcement and also through its control of the education system and often of the broadcast media has by far the greatest influence in reinforcing and shaping the moral environment of individuals and hence on the assessments they make. 
However, the degree of consensus evident at the national level is not replicated at the international level. Given that the Code is seeking to regulate behaviour at the global level a particularly important question is whether it is possible to establish a universal set of values in relation to doping and whether the 'spirit of sport' is such a universal value. As Bartels et al. (2015, p.499) observe 'Theories of morality typically try to identify universal moral principles while also accommodating differences in judgment and choices across settings and peoples'. On most moral issues there is little evidence that universal moral principles exist, while such evidence as there is suggests that there is a moderately high degree of uniformity of moral judgment within broadly homogeneous social groups (defined primarily by nationhood). Evidence of value variation exists not only in relation to relatively trivial matters such as how respect for senior colleagues in an organization is expressed (for example, bowing in Japan, but not in the UK (Morrison and Conway 1995)), but also in relation to more serious matters such as contraception and abortion (Riddle 1997) and extremely serious matters such as freedom to acknowledge one's own sexuality (Sadgrove et al. 2012).

There is also much evidence of variation between countries in public attitudes towards a range of forms of behaviour. In an analysis of the foundation on which moral judgments were made by middle class Indians and Americans Miller and Bersoff (1992) found that the Indian respondents gave greater weight to interpersonal expectations (particularistic obligations/loyalty) whereas Americans gave greater weight to disinterested rational 'justice' expectations. In a similar study Ginges et al. (2011) found variation in the foundations for moral judgments between Israelis and Palestinians. In relation to gender equality Mashhour (2005) found significant 
differences in attitudes and law towards divorce and polygamy in Tunisia and Egypt with the former adopting a significantly more liberal interpretation of Sharia law. Alter and Vargas (2000) examined the capacity of European Union law to bring about change in policy at the domestic level in relation to gender equality and noted the extent to which the impact of EU law varied across the member states.

The extent to which variation in policy continues to persist on many issues in the European Union is perhaps the strongest evidence of the difficulty of achieving uniformity of policy implementation in relation to doping at an international level. Political and civic culture, governmental priorities and state capacity all militate against uniformity and highlight the challenge of achieving compliance with the World Anti-Doping Code. This conclusion notwithstanding it should be borne in mind that differences between countries are not fixed even if they are slow to change. Over the last seventy years or so UN conventions on human rights, the rights of the child and the rights of people with disabilities have set the international agenda for policy debate and have arguably led to normative change aligned more closely with the articles of the various conventions (Clark 2010, Harpur 2012, Weiss and Thakur 2010).

\section{Public opinion and doping in sport}

The data available on the attitude of the public towards aspects of doping in sport are relatively scant. In addition, the variety of aspects of doping covered by recent research and the range of countries studied makes comparison between countries 
difficult with the result that conclusions have to be drawn with considerable caution. However, there is a steady increase in the volume of research with some undertaken by national anti-doping organisations. The Japan Anti-Doping Agency (JADA), for example, in order to inform the design of its education programmes has, since 2009, conducted a number of annual surveys of senior and youth elite-level athletes and the general public to gather data on attitudes towards doping, fair play and integrity in sport (JADA 2014; 2015, Yamamoto 2016). Nevertheless, with the exception of Japan, most data on public opinion come from a narrow range of Northern European and Anglo-Saxon countries.

In their study of public attitudes in Norway Brevik et al. (2009) reported that $79 \%$ of the sample (428 aged between 18 and 35) opposed the use of PEDS in sport. Opinion was similar irrespective of the type of PED being used. A subsequent study of public opinion on Norway (Solberg et al. 2010) reported an even stronger rejection of doping in sport with $94.5 \%$ of the public (sample size 925 ) considering the use of erythropoietin (EPO), and 98.6\% considering the use of anabolic steroids, unacceptable. A broadly similar set of findings was reported by Singhammer (2012 2013) in a large sample of the Danish general public (1703 respondents aged 15-60). However, the questions were only indirectly linked to participation in sport. Only $5.4 \%$ considered it acceptable to use performance enhancing drugs to 'enhance physical strength and endurance' and only $2.1 \%$ would accept the use of steroids. The research by Van Reeth and Lagae (2013) gathered data from a cross section of 1949 respondents from the Flanders region of Belgium on doping in cycling. In line with the research reviewed so far Flemish respondents offered strong criticism of doping by athletes (around $80 \%$ for the series of questions). In a large sample of 2520 
Australians Engelberg et al. (2012) found evidence of strong opposition to doping in sport and these findings were reinforced in a subsequent survey of 1265 Australians which reported that over $90 \%$ opposed the use of PEDS in sport and opposed their legalization (Partridge et al. 2014). Nocelli et al. (1998), in a survey of 1201 Swiss aged between 18 and 74 years conducted in 1995, found that $84 \%$ considered doping in elite sport to be either 'a somewhat serious problem' or a 'very serious problem'. In the only time series study Stamm et al. (2008) traced the development of Swiss public opinion towards doping and found a growing awareness of the issue of doping and increasing support for a comprehensive anti-doping strategy from the first survey in 1995 to the most recent in 2004 in which over $90 \%$ of the public considered doping to be damaging to the image of sport.

More relevant to this study is the research of Mazanov et al (2012) that investigated the basis on which people opposed the use of PEDS. In a 168 person sample of the general public in Australia Mazanov et al. found that the most frequently cited reasons for opposing the use of PEDS in sport were the values associated with 'ethics, fair play and honesty' followed by 'respect for self and other participants' and 'respect for rules and laws'. Opposing the use of PEDS because of potential harm to health was ranked seventh out of eleven possible reasons although it was ranked second among the small number (11\%) who did not follow sport. A study in the same year by Engelberg et al. (2012) reported that fairness was the primary reason for opposing doping in sport (77\%) with only $20 \%$ selecting the risks to health as the primary reason for opposing doping. Fairness was also the main justification for supporting anti-doping policy in Switzerland (Stamm et al. 2010). 
Van Reeth and Lagae (2013, p.13) reported 60\% in favour of treating doping as a criminal offence and concluded that 'The most important findings are that cyclinginterested people are less convinced that doping use should be considered a criminal offence'. Opinion regarding criminalization was less clear in the survey of Australian public opinion by Engelberg et al. (2012). Their results showed opinion split with just over half (53\%) agreeing that PEDS use should be criminalised. Public opinion in favour of more severe sanctions was more evident in Norway and also in Switzerland with a strong body of support for the withdrawal of commercial sponsorship (Solberg et al. 2010, Stamm et al. 2010).

Unsurprisingly there was significant within-sample variation in opinion. Brevik et al. (2009) found that men (52.9\%) were more likely than women (42.9\%) to support an increase in investment in anti-doping efforts. Mazanov et al. (2012) found little difference in the ranking of reasons for opposing doping in sport between men and women although for women 'respect for self and other participants' was the primary reason whereas for men it was the values of 'ethics, fair play and honesty'. Singhammer (2012) also found differences in the responses given by men and women. In general, women were markedly less supportive of the use of performance enhancing drugs irrespective of the particular context (such as, to increase sexual libido, to enhance cognitive ability or to enhance physical strength and endurance). Singhammer also noted variation by age according to which more permissive attitudes peaked at around the age of 25 and then declined, but found little variation by education or level of participation in sport. Solberg at al. (2010) found that opposition to doping grew stronger with each age group. Van Reeth and Lagae (2013, p.19) reported a number of statistically significant differences in their sample of Flemish 
public opinion: 'Women and older people attach greater value to health issues and consequently have a much more outspoken anti-doping attitude than men and younger people.

Insofar as there is a pattern in these studies it is clear that there is a high level of public support for anti-doping. What is also clear is how little is known about the basis for the condemnation of PEDS use. In those studies that explored reasons for opposing PEDS use 'fairness' was regularly mentioned although it was not clear whether respondents were conceptualizing 'fairness' as a universal or as a sportspecific or culture-specific value. Understanding such differences would be of paramount importance not only to an understanding of the extent to which the public embraces generalised anti-doping sentiments, but also as an indication of the best context within which to seek to consolidate moral opposition to doping.

\section{Cultural values in Japan and the UK}

In his analysis of the cultural basis of the values that underpin social relations mentioned above Fiske argued that communal sharing was the dominant model in Japan while market pricing was dominant in the UK. Generalising about complex industrial/post-industrial societies should always be cautious, but an overview of the foundation of social values in the two countries is important as a context for the presentation of the findings of this research. Japan is often portrayed as a broadly secular society, heavily influenced by Confucian values and characterised as hierarchical, tightly socially interconnected and collectivist rather than individualist (Trommsdorf 1983, Reischauer and Jansen 1995, Martin and Stronach 2017). The 
persistence of collectivism in the face of modernization was confirmed by Hamamura. Although Hamamura (2011, pp.16-17) found some evidence of increased individualism he concludes '.. these findings confirm ... continuing emphasis on group orientation, social harmony, and obligation.' He further notes that 'the importance of social obligations has increased, whereas respect for individual rights has become less important. ...Perhaps the most intriguing aspect of this research is the persistence of collectivism in Japan' (Hamamura 2011, pp.14 \& 16). By contrast the UK has been characterised as increasingly individualist, anti-collectivist and neoliberal. As noted in the 2013 British Social Attitudes Survey, 'The last three decades have seen a dramatic decline in support for welfare benefits aimed at disadvantaged groups, particularly the unemployed. Britain is more inclined than it was in the 1980s to feel that people should stand on their own two feet economically' (NatCen 2013, p.xviii). However, economic liberalism and an increasing preference for low taxes and more limited role for the state is combined with social liberalism and a, perhaps selective, tolerance for diversity (Paxman 1999, Ford 2008). It is upon the likely different sets of cultural values that the current comparative research between Japan and the UK on the relationship between public opinion and integrity and sport is based.

\section{Public opinion and integrity in sport in Japan and the United Kingdom}

Methodology 
The data analysed in this section were collected in Japan in 2015 and in the UK in 2016. JADA commissioned the Mitsubishi Research Institute to conduct the survey in Japan and YouGov to undertake the UK data collection. Both surveys were designed to gather opinion not only about the use of PEDS, but also about broader aspects of integrity in sport. The questions and the eight actions/scenarios were identified by JADA and related directly to their current concerns with aspects of integrity in sport. The Japanese survey included 4733 respondents and the UK survey 4092 respondents. Both data sets were collected on-line from survey panels (monitoring pools) maintained by the two companies. Both samples required some adjustment in the analysis of data and caution in interpretation. With regard to the Japanese data there was a substantial over-representation of respondents in the 15-19 age group and also an over representation of respondents from the Tokyo area. In contrast there was a substantial under-representation of the 15-19 age group in the UK data (see Table 2) as well as the 15-19 age group being small in absolute numbers. The geographical representation of respondents in the UK was broadly in line with the actual distribution of the population.

Table 2 about here

A further complication with the data was that while the questionnaires were comparable in terms of questions asked there were difference in the way in which some responses were recorded. For example, in questions in which respondents were offered a range of alternative responses (such as 'When thinking about sport in general which two or three, if any, of the following values do you think are the most important') the UK data were collected by respondents being offered a yes/no option 
for each value whereas in Japan the maximum number of values that could have been selected had been fixed at three and the values were ranked.

The translation of the surveys also provided a challenge. Comparative research that involves asking respondents to pass judgment on complex moral issues is far from easy. No matter how carefully the researchers design the questions and how sensitively they are translated there is always the possibility that interpretation of the question by respondents will differ from the meaning intended by the researchers. Even the most carefully designed questionnaires will elicit different interpretations of concepts such as 'fair', 'unfair' and 'respect' dependent upon the respondents level of education, past experiences and cultural reference points (see Kahane and Shackel 2010, O'Hara et al. 2010). The survey on which this analysis is based was designed in Japan and translated into English for the UK survey. Considerable care was taken in the translation in order that the questions would, as far as is possible, convey the same meaning in both countries. In an effort to retain the same meaning when translated into English some of the questions lacked the finesse of colloquial English. The English translation of the Japanese survey is in the Appendix.

Data were gathered in relation to eight questions designed to elicit opinions regarding issues of integrity in sport using a five point Likert scale: 'very fair', 'fair', 'neither fair nor unfair', 'unfair' and 'very unfair'. The responses were disaggregated by age, gender, participation in sport, watching sport live and on television or listening on radio. Cross tabulation was conducted between the independent variables of gender, age, participation in sport and TV/radio consumption of sport and the dependent variables of opinions towards the various actions. 


\section{Findings}

Table 3 provides an overview of the aggregate data related to participation and interest in sport by gender and age. With regard to participation UK respondents, both male and female, were over 50\% more likely than Japanese respondents to participate three or more times per week and Japanese respondents were over 50\% more likely to 'never' participate in sport. This pattern was maintained across age groups apart from among the 60-79 cohort where participation patterns were similar. Both sets of respondents exhibited broadly similar patterns of watching sport at a venue. In terms of watching sport on television or listening to sport on the radio the differences between the two sets of respondents are slight although the UK has a larger proportion of respondents, particularly among women, who stated that they 'never' watched/listened to sport.

Table 3 about here

Attitudes towards doping and related ethical issues in sport

Respondents were asked two questions related to their attitudes towards doping in sport. The first asked 'Imagine that you are an athlete, how fair or unfair do you think the following things related to sport are?'. One of the 'things'/actions was 'Taking an illegal substance (i.e. any substance prohibited by the WAD Code) as you know your opponent has done the same'. Of those who responded to this question in Japan $84.4 \%$ (2711) considered this action either 'unfair' or 'very unfair'. In the UK a 
smaller proportion of the sample responded to this question $(21 \%)$, but of those that did respond a similar proportion, $81.5 \%$ (697) considered the action to be either 'unfair' or 'very unfair'. The second question sought to elicit the reason for the answers given, 'In the previous question you said that "Taking an illegal substance (i.e. any substance prohibited by the WAD Code) as you know your opponent has done the same" is either 'Unfair' or 'Very unfair'. Which one of the following best describes why you think this is generally unfair?'. In both countries the most common bases for opposition to doping in this context were the 'values of sport' or the 'spirit of fair play' rather than other possibilities such as potential damage to an athlete's health or that doping conflicts with the values of the country (see Table 4). However, while $46.5 \%$ of UK respondents opposed doping on the basis that it undermines the spirit of sport Japanese respondents were more likely to refer to the spirit of fair play. Japanese respondents also mentioned the values of their country more frequently than UK respondents as a basis for opposition. Given that the concept of the 'spirit of fair play' could be seen as a more universal social value and not a specific value of sport it tends to reinforce the view that in Japan the primary reference point for moral judgments in relation to sport is the set of wider social values. In the UK sport is arguably seen as a distinct reference point for moral debate and for the expression of moral values. However, this does not mean that in the UK sport values are different from general social values merely that sport as a moral reference point has a strong profile in the UK (Mangan and Walvin 1987, Birley 1993, Watson et al. 2005).

Table 4 about here 
When the data were analysed by the extent of participation in sport the most striking observation was the lack of substantial variation between those who participated frequently (once or more a week or one to three times a month) and those who rarely if ever took part in sport or sport-related physical activities. The analysis of responses with respect to sports participation is important as one would expect participants to have a different moral reference point - one more strongly sport-informed - than nonparticipants. However, the data did indicate that those Japanese respondents who participated more frequently in sport were slightly more likely to refer to the 'spirit of sport' as the basis for their opposition to doping (Figure 1). Among UK respondents the 'spirit of sport' remained the most frequently mentioned reason given both by those who participated frequently and those who participated in sport rarely or never (Figure 2).

Figures 1 and 2 about here

Further evidence of the consistency of opinion across various social characteristics was provided by the examination of opinion towards doping across ages. There was minimal variation in opinion across the age groups in both Japan and the UK. In Japan, as well as the 'spirit of fair play' (frequency of mention by age $47 \%-53 \%$ ) some weight was given to the view that doping 'undermines the spirit of sport' (17\%$20 \%)$ and that it 'harms an athlete's health' (14\%-18\%). In contrast, the data from the UK show that in addition to all age groups viewing doping as undermining 'the spirit of sport' (39\%-54\%) a broadly similar weight was given to the view that doping is 'against the spirit of fair play' (37\%-42\%). What is also notable is the lack of emphasis on harm to the athlete's health among UK respondents (2\%-5\%). 


\section{Perception of the values of sport}

Information about the values that respondents considered to be most important in relation to sport was provided for both countries with the results summarised in Table 5. As can be seen there is little variation in the responses of males and females in either country. Japanese men emphasised the value of sport in meeting the needs for physical activity in daily life more than Japanese females. UK males emphasised more than UK females the value of sport in learning to respect rules (see earlier comment about the marketing pricing rule-based nature of UK society discussed by Fiske 1992). There are though some interesting contrasts between the two countries with Japanese respondents giving more than twice the weight (17\%) to the value of sport in developing human movement for daily life than UK respondents $(8.2 \%)$ and the value of sport in helping people to learn to work toward goals $(20.8 \%$ by comparison with the UK score of 7.9\%). UK respondents gave greater weight to the value of sport to the local and global community, as a means of learning about fair play and as a source of friendships. These differences might be explained in part by the long history in the UK (dating back to the 1980s) of using sport (and public investment in sport) as an instrument to achieve social objectives such as improved behaviour among the young, community integration and safety.

\section{Table 5 about here}

When the data were analysed in relation to the level of participation in sport the most striking observation was again the lack of notable difference between the four levels 
of participation within the two countries, but especially among the Japanese respondents. Irrespective of the extent of participation Japanese respondents valued health improvement and the achievement of goals (both transferable benefits to other aspects of life) whereas the UK respondents gave greater weight to the values of fair play, and teamwork and friendships. Interestingly, in the UK the greatest variation in responses when measured by participation in sport was in relation to the value of 'fair play' with those who participated three or more times a week being the least likely to identify this value as important (17\%). Those who participated 1-3 times a month identified 'fair play' as the most important value (24\%).

Public opinion of eight ethical issues

In order to obtain a more nuanced understanding of the foundation for ethical judgments on sports issues and the nature of those judgments respondents were asked to assess the fairness of the following eight actions/scenarios:

1. Taking an illegal substance (i.e. any substance prohibited by the World AntiDoping Code) as you know your opponent has done the same

2. Taking the same illegal substance (i.e. any substance prohibited by the World Anti-Doping Code) but receiving a longer ban from competing compared to athletes in other sports who took the same substance due to different sports' anti-doping rules at international competitions

3. You could not sleep well the previous night before a competition so in the morning you drank an energy drink which claimed to increase your stamina 
4. Unlike other athletes, you have access to the latest sport technology in your sport and are now winning competitions

5. You used to wear glasses for competitions, but had laser eye surgery. You improved your performances and are now winning a number of competitions

6. You lose a preliminary round match intentionally in order to avoid a tough opponent in the next round

7. You intentionally put your opponent at a disadvantage (i.e. doing something that is allowed but is considered strategic or tactical play)

8. You make fun of a rival during a competition

Figure 3 provides an overview of the relationship between frequency of participation in sport and assessments of the eight actions.

Figure 3 about here

There are no substantial or consistent differences in assessments between those who play sport more frequently ( 3 or more times a week) and those who never play sport. As noted above, this is interesting as one would expect these two groups to have different moral reference points - one more strongly sport-informed and the other less sport-informed. One explanation is that the decision about what constitutes integrity and 'moral' behaviour in sport is the product of the attitudes towards integrity and the moral values found in wider society. In other words sports' values are not so distinct from those found in other areas of social life. Figures 4 and 5 provide a similar overview of opinion but by gender and age. As can be seen in Figure 4 the proportion 
of male respondents who assess an action involving substances as 'unfair' or 'very unfair' (the first three sets of data in Figure 4) generally increases with age although 'taking an energy drink because of a poor nights sleep' is considered 'fair' by the majority in all age groups and in both countries. In contrast, the proportion assessing the use of technology and laser eye surgery as 'unfair' generally declines with age perhaps because older age groups are increasingly reliant on technology, especially medical technology, in their daily lives.

The lower proportion of younger respondents who assess losing intentionally as 'unfair' might be explained by their greater familiarity with perceived need by players and teams to distinguish between events in an increasingly crowded sporting calendar or by the stage of development of their moral sensibilities at which they are less attuned to broader community values (see Kohlberg \& Hersh 1977, Snarey 1985, Hart \& Carlo 2005). It is interesting that 'making fun of a rival' was considered 'unfair' by a higher proportion of all age groups in both countries than either losing intentionally or deliberately putting an opponent at a disadvantage. One possible explanation is that the two latter actions are seen as acceptable professional tactics whereas mocking a rival is a demonstration of a lack of respect for a fellow professional. A second explanation that relates to 'putting an opponent at a disadvantage' is the difficulty that some respondents might have had in interpreting this question.

Figures 4 and 5 about here

As mentioned above all 'actions' were introduced by the respondent being asked to 'Imagine you are an athlete, how fair or unfair do you think the following things 
related to sport are?' (see data summary in Table 6). The first action was, 'Taking an illegal substance (i.e. any substance prohibited by the World Anti-Doping Code) as you know your opponent had done the same'. There was little difference in the opinions expressed by Japanese males and females with $86.1 \%$ and $82.5 \%$

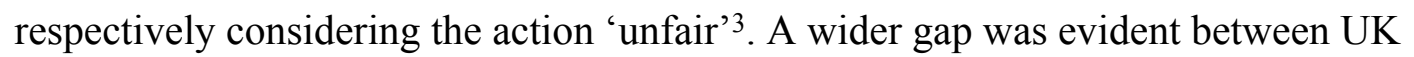
males and females with almost a quarter (23.3\%) of UK males considering the action 'fair' by comparison to only $14.9 \%$ of UK females. While the proportion of Japanese males $(86.1 \%)$ who considered the action to be 'unfair' was almost 10 percentage points higher than UK males $(76.7 \%)$ the pattern was reversed for Japanese $(82.5 \%)$ and UK females $(85.1 \%)$ with the latter being slightly more inclined to consider the action 'unfair'. With regard to changes in opinion with age the pattern in both countries was the same insofar as the proportion of respondents that considered the action 'unfair' increased with age and was almost identical for the 60-79 age group (Japan 89.3\%, UK 90.3\%)

Table 6 about here

The second issue asked respondents to assess a situation where an athlete 'Took the same illegal substance but received a longer ban'. There were few significant differences in the responses either within or between the countries. A higher proportion of female respondents than male in both countries considered the action 'unfair' although the differences were not great. Differences by age were also modest and that between the UK and Japan within the 15-19 age group needs to be treated with great caution as the number of UK respondents in this age group was small. With

\footnotetext{
${ }^{3}$ In this section the term 'unfair' refers to the aggregation of 'very unfair' and 'unfair' responses. Similarly the term 'fair' is an aggregation of 'very fair' and 'fair' responses.
} 
regard to the third issue (an athlete who took an energy drink) the most significant findings were that while UK and Japanese females had similar opinions UK males (77.3\%) were more likely to assess the action as 'fair' than Japanese males (66.5\%). UK respondents were also consistently more likely than Japanese respondents to assess the action as 'fair' across the four age groups.

In the fourth scenario (athlete who had obtained access to the latest technology) overall opinion was similar with just over one-third of the respondents in both countries (Japan 38.9\% and UK 35.8\%) considering the action 'unfair'. However, Japanese males were almost 10 percentage points more likely to consider the action 'unfair' than UK males. The responses from females were reversed but the gap between the countries was much narrower. The proportion considering the action 'unfair' generally declined with age although the change was not dramatic.

A situation where an athlete had had laser eye surgery and was now winning competitions was the fifth action in relation to which there was a strong opinion in both countries that the action was 'fair' ( $86.8 \%$ in Japan and $95 \%$ in UK). A larger proportion of both UK men and women and UK respondents from all age groups than Japanese respondents considered the action to be 'fair' while in both Japan and the UK the proportion assessing the action as 'fair' increased with age. With regard to the sixth action (athlete loses a preliminary round intentionally) a significantly higher proportion of Japanese respondents (41.6\% - UK-29.6\%) considered this action to be 'fair' with the gap being widest among females with $37 \%$ of Japanese females considering the action to be 'fair' in contrast with $21.1 \%$ of UK females. Males in both countries were much more likely than females to assess this action as 'fair'. The 
gap in opinion between the two countries, which was widest for the 20-39 age group, closed slightly across the older age groups.

The UK respondents were much more likely than the Japanese respondents to assess the action of intentionally putting an opponent at a disadvantage as 'fair' (Japan $49.8 \%$, UK 60.7\%). Males in both countries were more likely to consider the action as 'fair' (males: Japan 57\%, UK 65\%; females: Japan 42.3\%, UK 56.4\%). The proportion considering the action 'fair' declined with age, but more sharply in Japan.

The final action (an athlete who makes fun of rival during competition) produced a very similar set of responses in both countries. Only $31 \%$ and $29 \%$ of Japanese and UK respondents respectively considered the action 'fair' with there being little variation by age. There was some difference by gender with male respondents in both Japan (36.2\%) and the UK (36.1\%) more likely than female respondents (Japan $25.9 \%$, UK $20.5 \%$ ) to assess the action as 'fair'.

\section{Discussion and conclusion}

As mentioned in the introduction an understanding of the relationship between public opinion, domestic rule/law-making and athlete education is important because of: WADA's encouragement of governments to support the Code with domestic legislation; our lack of knowledge of the extent to which WADA-defined values, such as the spirit of sport, are recognised at the general societal level; and the need for 
clarity regarding the extent to which the spirit of sport can be used as a universal foundation for values-based anti-doping education.

Research on the relationship between laws/rules and public opinion indicate that, for the most part, law/rule-making responds to and follows public opinion (e.g. Thomas et al. 1976). Furthermore the sanction applied for a breach of laws/rules also tends to be influenced by public opinion. The research did identify some occasions when laws were introduced which helped to shape public opinion about particular behaviours such as smoking in public places (Rozin 1999). What can also be inferred from research is that the strength of the relationship between public opinion and law/rulemaking depends on the clarity of the issues or actions under consideration. Much of the existing research into the public's view of the seriousness of issues and the sanction that should be applied uses examples of well-known and relatively clear cut actions such as theft, sexual assault and smoking marijuana rather than more complex issues such as corporate negligence, fraud and tax avoidance/evasion. With regard to laws/rules on the use of PEDS the various iterations of the World Anti-Doping Code and the associated good practice guidance documents have arguably tended to reduce the clarity of the issue (e.g. in relation to the critieria for mitigation of sanctions and the granting of TUEs).

The general literature on law/rule-making and public opinion also makes it very clear that there are no universal principles regarding morality and that attempts to introduce global regulations such as the World Anti-Doping Code (as well as other UN Conventions such as those on the rights of the child or human rights) are mediated by a series of cultural factors the most important of which is the state and its institutions. 
Other mediating factors include gender, religion and political values. As is evident from the current research the introduction of new rules and the educational programmes designed to reinforce anti-doping values need to be designed to complement and draw upon the cultural context in which they will operate. Even in countries, such as Japan and the UK, that share many common features (regular host of mega-sport events, strong government commitment to elite athlete success and active NADO) the ethical foundation shaping attitudes to a range of sport-related issues including doping can vary considerably.

Japan is sometimes portrayed as a more homogeneous society than many others including the UK. While the analysis of the survey data does indeed present a picture of Japan as a country where attitudes towards doping, high performance athletes and sport are broadly uniform across gender, age groups and level of interest and participation in sport much the same conclusion can be drawn from the analysis of the data relating to the UK although there are some differences between males and females in both countries in the emphasis placed on particular qualities and values. However, these differences correspond to the findings in similar research in other policy areas as discussed earlier.

The most notable difference between the two countries and one that has implications for anti-doping policy design is the extent to which moral positions are drawn from broader society or from the sport sub-sector. In Japan the data indicate that the primary reference point for respondents when deciding on the morality of certain types of behaviour in sport was a set of broad social attitudes and values. In contrast the UK respondents were more likely to refer to values that were more specific to a 
sporting context. However, despite the different sources of their value systems the respondents in both countries were broadly similar in the strength of their condemnation of doping in sport and other forms of ethically questionable behaviour. As mentioned previously the reason for the different sources of their assessments might reflect the greater frequency and prominence of issues of ethical sporting behaviour in the UK and the longer tradition of using sport and sporting metaphors in debates about morality in other spheres of social life such as business and politics.

In Japan it would seem that the strategy for ensuring commitment to anti-doping is more likely to be successful if it is emphasised that sport is an integral part of society and should therefore abide by the conventional norms and values of everyday life. In contrast, sport in the UK appears to have a more distinctive and stronger profile and acts as a reference point for behaviour outside the sport context. In other words sport is seen as the quintessence, albeit in an idealised form, of broader societal morality. The strategy for reinforcing public commitment to the Code in the UK would therefore be to argue that the Code is indeed the encapsulation of the 'spirit of sport'. However, the review of the literature on the source of ethical values indicates that society in general and sport in particular are only two possible sources with others being (extended) family, status group and religious affiliation. If adherence to the Code is to be strengthened among the general population as well as among athletes and national sport organisations it is highly unlikely that the narrow appeal to respect the 'spirit of sport' will be sufficient (or even understood) in many countries. It is more likely that anti-doping policy will need to be justified in relation to a range of moral reference points such as established societal norms (such as Confucianism), religious beliefs (for example Islam, Hinduism and Catholicism) through illustration 
within the International Standard for Education.

In both Japan and the UK there was a generally high level of consistency of opinion regarding the unacceptability of doping whether the comparison was by gender, age or participation in sport. However, there were gender differences in the basis of the assessments of the morality of sport issues with women being more concerned with the impact of actions on others and men more influenced by impact on the athlete and the relationship of the action to the rules and values of sport. In both Japan and the UK the most common bases for opposition to doping were the values of sport or the spirit of fair play rather than other possibilities such as potential damage to an athlete's health.

There were interesting and significant differences in the assessment of the morality of the various issues presented to respondents. While there was a clear majority in both countries who considered the taking of illegal substances either 'unfair' or 'very unfair' there was a greater willingness to assess as 'fair' or 'very fair' actions such as taking an energy drink, laser eye surgery and access to the latest technology - all of which would give an advantage in a sporting context. One possible explanation for the assessment of the use of the latest technology as 'fair' might be that it has been normalised in successive Olympic Games (Burkett 2010, Dyer 2015) and, perhaps more importantly, increasingly normal in everyday life. Medical interventions such as laser eye surgery are increasingly seen as mainstream alternatives to glasses and contact lens. More generally, energy drinks, technology and advanced medical treatments are considered normal and not exceptional (in the way that using PEDS 
might be seen) in everyday contexts in contemporary Japanese and UK society. A second possible explanation is that supportive technology in general is more acceptable (normal and needed) by the older age groups. It is already acknowledged that the Code requires athletes to operate according to a set of values that are inconsistent with behaviour acceptable in wider society (such as using many over-thecounter health remedies), but as the divergence in acceptable behaviour widens due to the normalization of many health/body enhancement technologies it may become more difficult to persuade the general public that sport should operate to different values.

What the data suggest is that the general public assess the nature of an action in terms of their own experience and in terms of what is normal in their daily lives rather than necessarily in a narrow sporting context. Those actions that tend to be confined to sport (use of PEDS or making fun of a rival) and have only limited relevance in daily life were more heavily condemned as unfair than those that had a more easily recognizable everyday life equivalence such as losing a preliminary round intentionally (i.e. not doing your best on all occasions) and intentionally putting an opponent/rival at a disadvantage. These two actions elicited interesting differences between Japan and the UK with the UK respondents being much more critical of deliberately losing a preliminary round (i.e. not doing one's best to win), but were more accepting of intentionally putting an opponent at a disadvantage (perhaps more accepting of a wider range of actions to 'do one's best to win').

The challenge for those designing anti-doping programmes is to appreciate the need to take careful account of the primary moral reference point in a society and 
particularly the relationship of sport to society. Thus while the Code is a universal set of regulations the way in which it should be promoted needs to be aligned with a variety of cultural contexts. WADA's International Standard for Education provides some flexibility for anti-doping organisations to devise education programmes that will resonate with the domestic culture as the primary responsibility for the implementation of the ISE rests with National Anti-Doping Organisations. However, the ISE emphasises on numerous occasions that the focus for values education is the promotion of an understanding of the spirit of sport on the assumption that the value is understood and has global currency. As this research has shown these assumptions are questionable and WADA might be better advised to be more skeptical of the placeless universality claimed on behalf of the spirit of sport and show greater awareness of the variety of value-systems that exist across the globe and aim to link the World Anti-Doping Code with culturally resonant values within philosophies as diverse as Islam, Confucianism, American pragmatism and Hindu Advaita Vedānta.

\section{References}

Alter, K.J. and Vargas, J., 2000. Explaining variation in the use of European litigation strategies: European community law and British gender equality policy. Comparative Political Studies, 33(4), pp.452-482.

Bartels, D.M, Bauman, C.W., Cushman, F.A., Pizarro, D.A. \& McGraw, A.P., 2015. Moral judgment and decision making. In G. Keren \& G. Wu (Eds.) The Wiley handbook of judgment and decision making, London: J Wiley and Sons. 
Birley, D., 1993. Sport and the Making of Britain. Manchester University Press.

Bowers, D.A. \& Waltman, J.L., 1994. Are elected judges more in tune with public opinion? A look at sentences for rape, International Journal of Comparative and Applied Criminal Justice, 18 (1-2), 113-18.

Brevik, G., Hanstad, D.V. \& Loland, S., 2009. Attitudes towards use of performance enhancing substances and body modification techniques: a comparison between elite athletes and the general population, Sport in Society, 12(6), 737-754.

Burkett, B., 2010. Technology in Paralympic sport: performance enhancement or essential for performance?. British journal of sports medicine, 44(3), 215-220.

Burstein, P., 2003. The impact of public opinion on public policy: A review and an agenda. Political Research Quarterly, 56 (1), 29-40.

Clark, A. M., 2010. Diplomacy of conscience: Amnesty International and changing human rights norms. Princeton University Press.

Courtwright, D.T., 1997. Morality, religion and drug use. In A.M. Brandt \& P. Rozin (Eds.) Morality and health, New York: Routledge, pp. 231-250.

Doi, T.L., 1981. The anatomy of dependence (2 $2^{\text {nd }}$. Edn.), Tokyo: Kodansha. 
Dyer, B., 2015. The controversy of sports technology: a systematic review. SpringerPlus, 4(1), 524.

Dyer, B., 2015. The controversy of sports technology: a systematic review. SpringerPlus, 4(1), 524.

Engelberg, T., Moston, S., \& Skinner, J., 2012. Public perception of sport anti-doping policy in Australia. Drugs: education, prevention and policy, 19(1), 84-87.

Fairbank, J. K., Reischauer, E. O., \& Craig, A. M., 1973. Tradition and Transformation. George Allen \& Unwin.

Fiske, A.P., 1992. The four elementary forms of sociality" frameworks for a unified theory of social relations, Psychological Review, 99 (4), 689-723.

Ford, R., 2008. Is racial prejudice declining in Britain?. The British Journal of Sociology, 59(4), 609-636.

Gilligan, C., 1982. In a different voice: Psychological theory and women's development, Cambridge, MA.: Harvard University Press.

Ginges, J., Atran, S., Sachdeva, S., \& Medin, D., 2011. Psychology out of the laboratory: the challenge of violent extremism, American Psychologist, 66 (6), 507 519. 
Hamamura, T., 2011. Are cultures becoming individualistic? A cross-temporal comparison of individualism-collectivism in the United States and Japan, Personality and Social Psychology Review, 16(1), 3-24.

Hanstad, D.V. \& Loland, S., 2008. Athlete whereabouts information: similarities and differences in interpretation and implementation within NADOs, paper, Association of Anti-Doping Organisations, Lausanne, Switzerland.

Harpur, P., 2012. Embracing the new disability rights paradigm: the importance of the Convention on the Rights of Persons with Disabilities. Disability \& Society, 27(1), 114.

Hart, D., \& Carlo, G., 2005. Moral development in adolescence. Journal of Research on Adolescence, 15(3), 223-233.

Hood, R.W., Spilka, B., Hunsberger, B. and Gorsuch, R., 1996. The psychology of religion: an empirical approach, New York: Guilford.

Houlihan, B., 2014. Achieving compliance in international anti-doping policy: an analysis of the 2009 World Anti-Doping Code, Sport Management Review, 17 (3), 265-276.

Houlihan, B. \& Garcia, B., 2012. The use of legislation in relation to controlling the production, movement, importation, distribution and supply of performanceenhancing drugs in sport, report to UNESCO, Paris: UNESCO. 
Japan Anti-Doping Agency, 2015. A comparative research on attitudes towards 'fairness in sport' between different performance levels of Japanese athletes and nonathletes and a literature review on 'fairness', Tokyo: JADA.

Japan Anti-Doping Agency, 2014. Survey on 'Value of Sport' and 'Fairness in sport' in general public in Japan, Tokyo: JADA.

Kahane, G. \& Shackel, N., 2010. Methodological issues in the neuroscience of moral judgment, Mind and Language, 25(5), 561-582.

Kohlberg, L., \& Hersh, R. H., 1977. Moral development: A review of the theory. Theory into practice, 16(2), 53-59.

Mangan, J. A., \& Walvin, J. (Eds.)., 1987. Manliness and morality: Middle-class masculinity in Britain and America, 1800-1940. Manchester University Press.

Mann, R.E., Macdonald, S., Stoduto, G., Bondy, S., Jonah, B. and Shaikh, A., 2001.

The effects of introducing or lowering legal per se blood alcohol limits for driving: an international review, Accident Analysis and Prevention, 33, 569-583.

Martin, C. H., \& Stronach, B., 2017. Politics East and West: A Comparison of Japanese and British Political Culture: A Comparison of Japanese and British Political Culture. London: Routledge. 
Mashhour, A., 2005. Islamic law and gender equality - could there be a common ground": a study of divorce and polygamy in Sharia law and contemporary legislation in Tunisia and Egypt, Human Rights Quarterly, 27 (2), 563-582.

Mazanov, J., Huybers, T. \& Connor, J., 2012. Prioritising health in anti-doping: what Australians think, Journal of Science and Medicine in Sport, 15(5), 381-385.

Miller, J.G. and Bersoff, D.M., 1992. Culture and moral judgment: how are conflicts between justice and interpersonal responsibilities resolved?, Journal of Personality and Social Psychology, 62(4), 541-554.

Morita, A., 2011. Amae and Belonging-An encounter of the Japanese Psyche and the Waning of Belonging in America. Brigham Young University Journal of Public Law, $25(2), 341-350$.

Morrison, T. \& Conway, W.A., 1995. Kiss, bow or shake hands, Avon, MA.: Adams Media.

NatCen Social Research, 2013. British Social Attitudes Survey 2013, London: NatCen.

Nocelli, L., Kamber, M., François, Y., Gmel, G., \& Marti, B., 1998. Discordant public perception of doping in elite versus recreational sport in Switzerland. Clinical journal of sport medicine, 8(3), 195-200. 
O’Hara, R.E., Sinnott-Armstrong, W. \& Sinnott-Armstrong, N.A., 2010. Wording effects in moral judgments, Judgment and Decision Making, 5, 547-554.

Page, B.I. and Shapiro, R.Y., 1983. Effects of public opinion on policy, American Political Science Review, 77(1), 175-190.

Page, B. I., \& Shapiro, R. Y., 2010. The rational public: Fifty years of trends in Americans' policy preferences. Chicago: University of Chicago Press.

Partridge, B., Lucke, J. \& Hall, W., 2014. "If you're healthy you don’t need drugs": Public attitudes towards "brain doping" in the classroom and "legalized doping", Performance Enhancement and Health, 3(1), 20-25.

Paxman J., 1999. The English: A Portrait of a People. Harmondsworth: Penguin.

Pew Research Center, 2016. Changing attitudes on gay marriage. Available at: http://www.pewforum.org/2016/05/12/changing-attitudes-on-gay-marriage/ Accessed on $7^{\text {th }}$ January 2017.

Posiadala, D., Smorawinski, J., Pluta. \& Adrzejewski, M., 2010. Doping in recreation: Public view versusdeclared use amng people practicing various sports, Studies in Physical Cultural Culture and Tourism, 17(3), 261-268.

Reischauer, E. O., \& Jansen, M. B., 1995. The Japanese today: Change and continuity. Harvard University Press. 
Rozin, P., 1999. The process of moralization, Psychological Science, 10 (3), 218-221.

Sadgrove, J., Vanderbeck, R. M., Andersson, J., Valentine, G., \& Ward, K., 2012. Morality plays and money matters: towards a situated understanding of the politics of homosexuality in Uganda. The Journal of Modern African Studies, 50(01), 103-129.

Singhammer, J., 2012. Age and gender specific variations in attitudes to performance enhancing drugs and methods: a cross sectional study, Sport Science Review, 21(5-6), $29-48$.

Singhammer, J., 2013. Attitudes towards anabolic androgenic steroids among noncompeting athletes in various types of sports: a cross-sectional study, Sport Science Review, 22(1-2), 109-128.

Snarey, J. R., 1985. Cross-cultural universality of social-moral development: a critical review of Kohlbergian research. Psychological bulletin, 97(2), 202.

Solberg, H.A., Hanstad, D.V. \& Thøring, T.A., 2010. Doping in elite sport - do fans care? Public opinion on the consequences of doping scandals, International Journal of Sports Marketing and Sponsorship, 11(3), 2-16.

Stamm, H., Lamprecht, M., Kamber, M., Marti, B., \& Mahler, N., 2008. The public perception of doping in sport in Switzerland, 1995-2004. Journal of sports sciences, 26(3), 235-242. 
Thomas, K., 1997. Health and morality in early modern England. In A.M. Brandt \& P. Rozin (Eds.) Morality and health, New York: Routledge, pp. 15-34.

Thomas, C.W., Cage, R.J. \& Foster, S.C., 1976. Public opinion on criminal law and legal sanction: An examination of two conceptual models, The Journal of Criminal Law and Criminology, 67 (1), 110-116.

Thrasher, J.F., Perez-Hernandez, M.S., Swayampakala, K., Arillo-Santillan, M.A. \& Bottai, S.D., 2009. Policy support, norms and secondhand smoke exposure before and after implementation of a comprehensive smoke-free law in Mexico City, American Journal of Public Health, 100 (9), 1789-1798.

Trommsdorf, G., 1983. Value change in Japan, International Journal of Intervultural Relations, 7, 323-338.

Van Reeth, D. \& Lagae, W., 2013. Public opinion on doping in cycling: differences among population groups, Leuven: KU Leuven.

Wagner, U. \& Hanstad, D.V., 2011. Scandinavian perspectives on doping - a comparative policy analysis in relation to the international process of institutionalizing anti-doping, International Journal of Sport Policy and Politics, 3(3), $355-372$ 


\begin{abstract}
Watson, N. J., Weir, S., \& Friend, S., 2005. The development of muscular
Christianity in Victorian Britain and beyond. Journal of religion and society, 7.
\end{abstract}

World Anti-Doping Agency, 2012. Report to WADA executive committee on lack of effectiveness of testing programs (Chair Richard Pound), Montreal: WADA.

World Anti-Doping Agency, 2017. WADA Foundation Board takes decisive action on the way forward for the Agency and for clean sport, Press Release 18 May. https://www.wada-ama.org/en/media/news/2017-05/wada-foundation-board-takesdecisive-action-on-the-way-forward-for-the-agency-and Accessed 10 August 2017.

Weiss, T. G., \& Thakur, R., 2010. Global governance and the UN: An unfinished journey. Indiana University Press.

Wittlin, M., 2011. Buckling under pressure: an empirical test of the expressive effects of law, Yale Journal on Regulation, 28 (2), 419-469.

Yamamoto, M., 2016. Anti-Doping Education, Practice and Values, Taiikuka Kyoiku (Physical Education), October edition, Tokyo: Taishukan, pp.36-39.

Funding: The research on which this article is based was commissioned by the Japan Sport Agency, Government of Japan, in collaboration with the Japan Anti-Doping Agency as part of the Tokyo 2020 Olympic and Paralympic legacy project. The 
authors are grateful to the Japan Sport Agency for permission to use the data collected by the Mitsubishi Research Institute and YouGov. 


\title{
Appendix: Public survey in JAPAN
}

\author{
QUESTIONS \\ *texts in blue:
}

[japan1] How often, if at all, have you played sport or done physical exercise over the past year? (Please include any competitive sport, walking and light physical movement)

$<1>$ Three or more a week

$<2>$ One or two times a week

$<3>$ Between one to three times a month (i.e. more than once a month)

$<4>$ Between one and six times a year (i.e. more than once a year)

$<5>$ None at all

\#\# To those who answered 1-4 in japan1

[japan2 if japan1 in $[1,2,3,4]$ ] \{multiple order=randomize max=3\} Which two or three, if any, of the following are reasons why you have played sport/ done physical exercise over the past year? Please choose up to three answers.

$<1>$ For my health/ to improve my fitness

$<2>$ Because l enjoy it/ it is something to do in my spare time

$<3>$ Because I need to do more exercise

$<4>$ So I can challenge myself

$<5>$ To spend time with friends

$<6>$ To spend time with my family

$<7>$ To improve my ability and skills in sport

$<8>$ To improve how I look

<9> Because I've been inspired/encouraged by major sporting events (e.g. 2020 Tokyo

Olympics/ Paralympics)

$<10>$ Because it is a popular thing to do

$<11>$ Don't know

\#\# To those who answered 5 in japan1

[japan3 if japan1 in [5]] \{multiple order=randomize max=3\} You previously said that haven't done any exercise in the past year... <<br/ $>>$ Which, if any, of the following are reasons why you did not play sport/ do physical exercise over the past year? Please choose up to three answer options.

$<1>$ Because I don't have enough time (due to e.g. work or housework)

$<2>$ Because I am not (physically) strong enough

$<3>$ Because I am getting old/ Because of my age

$<4>$ Because I don't like physical exercise or sport

$<5>$ Because there is no place or facility near me to do sport

$<6>$ Because I don't have the chance to do any sport (e.g. because of social barriers)

$<7>$ Because I have no friends/ family to go with

$<8>$ Because it costs too much money

$<9>$ Because I do not have anyone to train/ instruct me

$<10$ fixed xor $>$ None of the above

$<11$ fixed xor $>$ Don't know

[japan4] Over the past year, approximately how often, if at all, have you watched a sport event in person at the venue? (This can include watching any free or paid-for major or local sporting event e.g. cheering along the road for a marathon, watching a football match in the stadium) 
$<1>$ Once a week or more

$<2>$ Between one and three times a month (i.e. more than once a month)

$<3>$ Between one and six times a year (i.e. a few times a year)

$<4>$ None at all

[japan5] Over the past year, how often, if at all, have you watched sport on TV or listened to sport on the radio? (Please only think about listening/ watching live or recorded matches and do NOT include watching highlights of sport on the news or sports documentaries)

$<1>$ Once a week or more

$<2>$ Between one and three times a month (i.e. more than once a month)

<3> Between one and six times a year (i.e. a few times a year)

$<4>$ None at all

\#\# Options 1 and 2 can both be selected

[japan6] \{multiple\} Have you ever watched the Olympic or Paralympic Games at an official stadium/ venue?

$<1>$ Yes, I watched at least one event at a 1964 Tokyo Olympic or Paralympic stadium/ venue

$<2>$ Yes, I watched at least one event at a different Olympic or Paralympic Games at one of the stadium/ venue

$<3$ fixed xor $>$ No, never

\#\# Options 1 and 2 can both be selected

[japan7] \{multiple\} Have you ever watched or listened to the Olympic or Paralympic Games on TV or on the radio? (Please only think about listening or watching live or recorded matches but do NOT include watching sports highlights on the news or sport documentaries.)

<1> Yes, I watched the 1964 Tokyo Olympic or Paralympic Games live or recorded on TV/ radio

<2> Yes, I have watched a different Olympic or Paralympic Games live or recorded on TV/ radio

$<3$ fixed xor $>$ No, never

[japan8] How happy or unhappy were you that the 2020 Olympic and Paralympic Games were awarded to Tokyo?

$<1>$ Very happy

$<2>$ Fairly happy

$<3>$ Fairly unhappy

$<4>$ Very unhappy

[japan9] \{multiple order=randomize $\max =3$ \} When thinking about sport in general, which two or three, if any, of the following values do you think are the most important? Please choose up to three answers.

$<1>$ Physical ability

$<2>$ Promoting health

$<3>$ Discipline and rules

$<4>$ Fair play and good sportsmanship

$<5>$ Setting and achieving goals

$<6>$ Building teamwork and friendship 
$<7>$ Contributing in a positive way to the local community

$<8>$ Contributing in a positive way to the global community

\#\# This only goes to those aged 15 and over

[japan10] \{grid roworder=randomize displaymax $=5$ \} Imagine you are an athlete, how fair or unfair do you think the following things related to sport are?

- [japan10_1] Taking an illegal substance (i.e. any substance prohibited by the World AntiDoping Code) as you know your opponent has done the same - [japan10_2] Taking the same illegal substance (i.e. any substance prohibited by the World Anti-Doping Code) but receiving a longer ban from competing compared to athletes in other sports who took the same substance due to different sports' anti-doping rules at international competitions - [japan10_3] You could not sleep well the previous night before a competition so in the morning you drank an energy drink which claimed to increase your stamina - [japan10_4] Unlike other athletes, you have access to the latest sport technology in your sport and are now winning competitions

- [japan10_5] You used to wear glasses for competitions, but had laser eye surgery. You improved your performances and are now winning a number of competitions

- [japan10_6] You lose a preliminary round match intentionally in order to avoid a tough opponent in the next round

- [japan10_7] You intentionally put your opponent at a disadvantage (i.e. doing something that is allowed but is considered strategic or tactical play)

- [japan10_8] You make fun of a rival during a competition

$<1>$ Unfair

$<2>$ Fair

$<3>$ Don't know

\#\# To those who said 'Unfair' to any of the above statements in Q10

[japan11_1_8 if japan10 in [1]] \{single order=randomize\} Which one of the following best describes why you think this is generally unfair?

$<1>$ Because it means there aren't equal conditions between the athletes

$<2>$ Because it is against the norm, principle, ethics of sport

$<3>$ Because it is against the values and norms of society

$<4>$ Because it disrespects the values of relationships with other humans

$<5>$ Because other competitors are not being respected

$<6>$ Because of the expectations of other people (e.g. parents, sponsors, fans etc.)

$<7>$ Because it is against my own values and beliefs

[japan12] \{single order=randomize Which one of the following best describes your opinion of doping in sport?

$<1>$ It undermines the spirit of sport

$<2>$ It is against the spirit of fair play

$<3>$ It harms the athlete's health

$<4>$ It is against the values of society

$<5>$ It is seen as a short-cut to the goal

$<6$ fixed $>$ Not sure 
[japan13] \{grid roworder=randomize displaymax $=6\}$ To what extent do you agree or disagree that the following messages have been successfully communicated about this country to other countries after Britain hosted the Tokyo 2020 Olympic and Paralympic Games?

- [japan13a] Japan is a society that generally respects high ethical standards

- [japan13b] Japan is a society that respects laws and rules

- [japan13c] Japan is a society that generally respects high ethical standards in sport

- [japan13d] Japan is a society that respects sporting rules and principles

- [japan13e] Japanese people have respectable personal values and principles

- [japan13f] Japan is a strong economic power

- [japan13g] Japan has close-knit communities and good infrastructure (e.g. buildings, transport)

- [japan13h] Japan is technologically advanced

- [japan13i] Japan is a traditional society

- [japan13j] Japan allows people to have an good lifestyle

- [japan13k] Japan promotes global peace and international development

- [japan13I] Japan tackles inequalities related to, for example, race, religion, political beliefs and gender

$<1>$ Strongly agree

$<2>$ Tend to agree

$<3>$ Neither agree nor disagree

$<4>$ Tend to disagree

$<5>$ Strongly disagree

[japan14] \{multiple order=randomize $\max =5\}$ Which, if any, of the following do you think are required to be a professional national athlete competing for your country? Please choose up to 5 answers.

$<1>$ Strong body

$<2>$ Strong mind

$<3>$ Perform well

$<4>$ Ability to win competitions or matches

$<5>$ Strong personality

$<6>$ Be a good role model to young people

$<7>$ Good decision-making skills

$<8>$ Pushing the limits of physical and mental health in honest ways

$<9>$ Enjoy sport

$<10>$ Emotion and passion for sport

$<11>$ A sincere attitude to sport

$<12>$ Respect for justice and fair play

$<13>$ Ability to face and overcome challenges

$<14>$ Hard work and determination

$<15>$ Follow the sport's principles or rules (e.g. anti-doping rules)

$<16>$ Have ethical values

$<17>$ Respect for others without discrimination

$<18>$ Respect for teamwork 